mispronunciation. An instance of this occurred within the lecturer's experience at Marlborough School not long ago: one stammering member of a certain form having communicated his defect to several of his schoolfellows. (4.) Bad teaching, and inattention to faults in their nascent condition. Many mothers think fit to accommodate their speech to farourite children by mutilating and defacing it ; keeping two vocabularies, one for the drawing-room, another for the nursery. This is a fatal source of imperfections, the more so as it is to be remarked that stammering never comes on till about the age of five years or more.

Lastly come peculiarities of an unconscious character akin to stammering-clucking, coughing, the reiterated interpolation of otiose syllables such as "er er," "ta ta"; even of definite words or sentences such as "you know," or the coarse expletive adjectives of habitual swearers. The lecturer cited a case within his own remembrance where an estimable clergyman had acquired the singular trick of unconsciously interlarding all his remarks with the involuntary phrase, "What a pity! what a pity!" in defiance of all sense and context.

Methods of cure were then adverted to. Probably no buman infirmity had been the object of such diverse or such blundering and unscientific treatment. Even so good a surgeon as Diefenbach cut we tges out of the tongue of the patient ; Itard made them speak holding a gold fork in their mouth; Serres advised a waving motion of the arms during speech; Bertrand caused them to regulate the words to a rhythmical motion of the fingers, or to keep time to a stick as in the orchestra. He also placed substances in the mouth. This had been done centuries before by Demosthenes, according to that unveracious gossip, Plutarch. These might be termed mechanical attempts at cure.

Next to them came musical methods, and foremost among them singing; it being well known that many confirmed stammerers sing with perfect articulation. Secondly, a so-called secret method, which consisted in either whispering or speaking in a gruff unmelodious tone. Thirdly, the very opposite of this as recommended by Marshall Hall, namely, chanting or monotoning. Fourthly, preceding all abrupt and consonantal sounds by a vowel such as $\mathrm{E}$, recommended by Arnott. Fifthly, the plan of running all the words of a long sentence into one, and thus acquiring as it were an articulatory momentum.

Intellectual or rational methods brought the lecture to a close. First among these is pausing and deliberateness. The stammerer may be compared mechanically to a steamship which overruns her screw, and treated similarly. Secondly, the imitation of good models, by reading in unison with an articulate speaker. Thirdly, and perhaps best of all, prefacing every sentence by a deep breath, which relaxes all the muscles of speech, and enables them to start fairly one against another. Fourthly, a plan was suggested which had succeeded admirably in the lecturer's experience, namely, that of learning a new language. For this purpose none was better than French. Its pronunciation is so thoroughly different from that of English, that it requires and establishes a totally new coordination of muscles. Moreover its mode of habitual acquirement is entirely different from that of English. Any one who will watch a French child just rising out of infancy must notice that whereas the character of an English child's incipient speech is "smudging" and confusion, the other's is slow, pompous, and deliberate. It is not till later in life that the French acquire that lightning-like rapidity of speech which is the terror of foreigners; while young they speak well and slowly. The third lecture ended with a few directions how to proceed in a case of stammering, and some suggestions as to the prospects of cure. As to the former, it is obviously desirable to examine carefully for the exact seat and the exciting cause of the defect; most of the systems in vogue having erred by exaggerating a particular treatment to the exclusion of others equally admissible. As to the latter, there is no doubt that stammering can be cured. This was proved by such instances as Demosthenes, Wilberforce, and Kingsley. But it was equally proved by the three names thus enumerated that to conquer the vicious habit required no usual amount of patience, ability, and determination.

\section{DISTRIBUTION OF ENERGY IN THE SPECTRUM}

$\mathrm{I}$ the reaction against the arbitrariness of prismatic spectra there seems to be danger that the claim to ascendency of the so-called diffraction spectrum may be overrated. On this system the rays are spaced so that equal intervals correspond to equal differences of wavelength, and the arrangement possesses indisputably the advantage that it is independent of the properties of any kind of matter. This advantage, however, would not ba lost, if ins ead of the simple wave-length we substituted any function thereof; and the question presents itself whether there is any reason for preferring one form of the function to another.

On behalf of the simple wave-length, it may be said that this is the quantity with which measurements by a grating are immediately concerned, and that a spectrum drawn upon this plan represents the results of experiment in the simplest and most direct manner. But it does not follow that this arrangement is the most instructive.

Some years ago Mr. Stoney proposed that spectra should be drawn so that equal intervals correspond to equal differences in the frequency of vibration. On the supposition that the velocity of light in vacuum is the same for all rays, this is equivalent to taking as abscissa the reciprocal of the wave-length instead of the wavelength itself. A spectrum drawn upon this plan has as much (if not more) claim to the title of normal, as the usual diffraction spectrum.

The choice that we make in this matter has an important influence upon the curve which represents the distribution of energy in the spectrum. In all cases the intensity of the radiation belonging to a given range of the spectrum is represented by the area included between the ordinates which correspond to the limiting rays, but the form of the curve depends upon what function of the ray we elect to take as abscissa. Thus in the ordinary prismatic spectrum of the sun, the curve culminates in the ultra-red, but in the diffraction spectrum the maximum is in the yellow, or even in the green, according to the recent important observations of Prof. Langley. If we wish to change the function of the ray represented by the abscissa, we can of course deduce by calculation the transformed curve of energy without fresh experiments. To pass from the curve with abscissæ proportional to wave-length to one with abscissæ proportional to reciprocals of wave-length, we must magnify the ordinates of the former in the ratio of the square of the wave-length, and this will give us an energy curve more like that ob tained with a prismatic spectrum.

There is another method of representation intermediate between these two, which is not without advantage. In the diffraction spectrum the space devoted to a lower octave (if we may borrow the language of acoustics) is greater than that devoted to a higher octave. In Mr. Stoney's map the opposite is the case. If we take the logarithm of the wave-length (or of the frequency) as abscissa, we shall obtain a map in which every octave occupies the same space, and this perbaps gives a fairer representation than either of the others. To deduce the curve of energy from that appropriate to the diffraction spectrum, we should have to magnify the ordinates in the ratio of the first power of the wave-length.

My object, however, is not so much to advocate any 
particular method of representation, as to point out that the curve of energy of the diffraction spectrum bas no special claim to the title of " normal."

\section{RAYLEIGH}

\section{THE ORNITHOLOGIST IN SIBERIA ${ }^{1}$}

THE ornithologists are certainly among the most enterprising of the seekers after truth. John Gould, the Birdman, is dead, but the same spirit which led him over the seas fifty years ago to investigate the then unknown Ornis of Australia still animates his brother birdmen. Mr. Henry Seebohm-a distinguished Member of the British Ornithologists' Union-has recently made two journeys into Northern Siberia, solely with the object of observing new forms and habits of bird-life and of collecting specimens. The scientific results of these expedi-

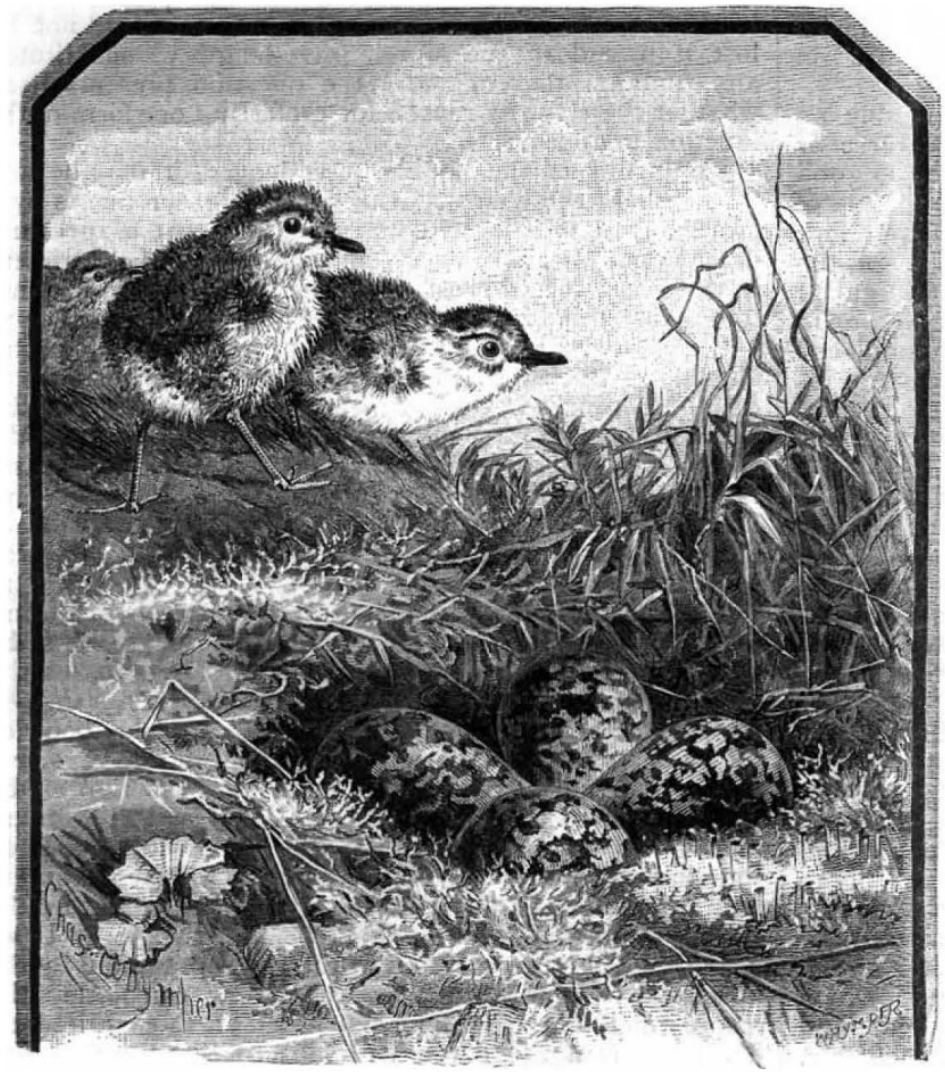

Fig. 1,-Grey Plover's rest and young.

tions have been published in the Ibis-the organ of the British Ornithologists' Union-which is now entering upon the twenty-fifth year of its existence, whilst a most interesting and attractive general narrative of the two journeys is given in the volumes now before us.

The first of these two expeditions, to the lower valley of the Petchora, in North-Eastern Russia, was made by the author in 1875 , in company with Mr. J. A. Harvie-Brown, a gentleman whose name is also known as that of an excellent field-naturalist. In order to be in time for the early spring migration, London was quitted on March 8, and the railway taken viâ St. Petersburg and Moscow to

I "Siberia in Europe: a Visit to the Valley of the Petchora, in NorthEast Russia ; with Descriptions of the Natural History, Migration of Birds \&c." By. Henry Seebohm, F.L.S., F Z.S. 8vo. (London: Murray, 1880.) "Siberia in Asia: a Visit to the Valley of the Yenesay, in East Siberia with Descriptions of the Natural History, Migration of Birds, \&c." By Henry Seebohm. 8vo. (London: Murray, 1882.)
Vologda. Hence it was rather more than four days and nights continuous sledging to Archangel, which was reached on March 18 at noon. At Archangel, the last civilised city on the route, nineteen days were spent in completing preparations for the further journey and in collecting information of what was considered by the good citizens of that place to be a most formidable undertaking. From Archangel to Ust-Zylma, on the Petchora, a distance of from seven to eight hundred miles lay before the travellers, and as the frost showed some symptoms of breaking up, did not at first promise to be easily got over. Fortunately they were just in time. A fortnight later the thawing snow became impassable, the winter road was destroyed, and the valley of the Petchora became cut off from all communication with civilised Europe for two months! Ust-Zylma, a long, straggling village of wooden houses on the right bank of the Petchora, some 300 miles from its mouth, was the headquarters of the party until June 15. The waiting for the "coming of spring" was rather tedious. 'Their first week at Ust-Zylma was not very encouraging from an ornithological point of view. After eight days' work, the list of identified birds in the valley of the Petchora only amounted to nine species, mostly of the commonest description. Three weeks had passed, and the thaw still made no progress; the summer seemed as far off as ever. It was sometimes hot in the daytime, but always froze again at night. On April 28 the first bird's-nest was taken (that of the Siberian Jay), but snow-shoes were still required to get about. It was not until May Io, in fact, that any real summer weather came, and it thawed in the shade as well as in the sun; but two days later it actually rained. The migrants then arrived in quick succession: swallows, swans, geese, gulls, wagtails, redstarts, pipits, and shorelarks, all were hurrying up from the south along with the first blush of spring. On May 20 , while the party were on a collecting expedition on the opposite bank of the Petchora, which they had crossed as usual on sledges, the grand crash came. The ice which had so long covered the river began to break up with a noise as of rumbling thunder, and cracks ran along it at the rate of a hundred miles in twentyfour hours. It was with great difficulty that the retreat was effected, and a few hours after home was reached the mighty river was in full flood, carrying its burden of pack-ice and ice-floes to the sea at the rate of six miles an hour. In a week's time the Petchora was entirely free from ice, and summer was upon them.

Collecting now began in earnest, and every day added to the number of interesting birds, and increased the variety of nests and eggs. On June 8, I43 eggs were taken and "blown" in the course of the day.

On June Io the journey down the Petchora was commenced in a large, partly-covered boat hired for the purpose, so that the naturalists might stop when they pleased for the purpose of collecting. The voyage was delightful. Everywhere the Blue-throat, the Redwing, the Brambling, the Fieldfare, the Little Bunting, and the Willow-warbler were common, whilst Three-toed Woodpeckers, Terek Sandpipers, and other rarities were making their nests and laying their eggs for the benefit of the travellers. Here one of the great discoveries of the expedition was made, which cannot be described better than in Mr. Seebohm's own words :-

"We were now a little to $t$ - north of the Arctic circle, and at three in the morning moored our boat on the 